\title{
Gestão de qualidade: um estudo de caso em uma biblioteca pública situada em Aracaju
}

O presente artigo visa a apresentar um estudo de caso sobre o tratamento de avaliação da qualidade em serviços oferecidos por bibliotecas públicas, buscando identificar a qualidade percebida pelos usuários na utilização dos serviços realizados em uma Biblioteca Pública, em Aracaju/SE. O estudo teve por objetivo analisar o fator de qualidade nos serviços oferecidos pela biblioteca, enfatizando os resultados dos serviços oferecidos, enfocando a satisfação dos usuários. Ao observar a gestão dessa Biblioteca, verifica-se que os serviços oferecidos pela unidade necessitam de melhorias, tornando-os mais acessíveis à comunidade onde ela está inserida, a fim de promover crescimento e comodidade para o usuário, resultando em ações que sejam válidas e contribuam também para a sua vida. Essa ação de melhoria deve estar alinhada à inclusão e educação digital, propondo reais mudanças no intuito de ajustar os serviços prestados com a qualidade para as bibliotecas públicas em geral. A metodologia adotada foi a bibliográfica, com a finalidade de fundamentar e embasar a pesquisa, tendo como base teses e dissertações disponibilizadas em sites e revistas periódicas digitais e bases de dados. Utilizou-se também para construção desse artigo o método qualitativoquantitativo, sendo esse método usado na realização de um levantamento de satisfação, através de aplicação de questionários aos usuários dos serviços e produtos oferecidos pela Biblioteca Pública, buscando identificar a percepção desses usuários ao nível de qualidade.

Palavras-chave: Gestão da Qualidade; Biblioteca Pública; Qualidade dos Serviços Bibliotecários; Satisfação do Usuário.

\section{Quality management: a case study at a public library located in Aracaju}

\begin{abstract}
This article aims to present a case study on the quality evaluation treatment in services offered by public libraries, seeking to identify the quality perceived by the users in the use of services performed in a Public Library in Aracaju / SE. The objective of the study was to analyze the quality factor in the services offered by the library, emphasizing the results of the services offered, focusing on user satisfaction. When observing the management of this Library, it is verified that the services offered by the unit need improvements, making them more accessible to the community where it is inserted, in order to promote growth and convenience for the user, resulting in actions that are valid and also contribute to your life. This improvement action should be aligned with digital inclusion and education, proposing real changes in order to adjust services provided with quality to public libraries in general. The methodology adopted was the bibliographical one, with the purpose to base and base the research, based on theses and dissertations available in digital periodical websites and journals and databases. The qualitative-quantitative method was also used to construct this article, and this method was used to carry out a survey of satisfaction, through the application of questionnaires to users of the services and products offered by the Public Library, seeking to identify the perception of these users at the level Of Quality.
\end{abstract}

Keywords: Quality Management; Public Library; Quality of Librarian Services; User Satisfaction.

Topic: Planejamento, Estratégia e Competitividade

Reviewed anonymously in the process of blind peer.
Received: $13 / 01 / 2018$

Approved: $22 / 04 / 2018$
Maria Inês Pereira Mota

Faculdade Maurício de Nassau, Brasil

http://lattes.cnpq.br/0269794339670478

ines.mota@bol.com.br

Guilherme Ferreira da Silva

Faculdade Maurício de Nassau, Brasil

http://lattes.cnpq.br/9750823542804001

ferreiraguilherme16@gmail.com

Tatiane Heinemann Böhmer

Instituto Federal de Sergipe, Brasil

http://lattes.cnpq.br/5481836411575976

tatianebohmer@gmail.com
Referencing this:

MOTA, M. I. P.; SILVA, G. F.; BÖHMER, T. H.. Gestão de qualidade: um estudo de caso em uma biblioteca pública situada em Aracaju. Entrepreneurship, v.2, n.1, p.28-35, 2018. DOI: http://doi.org/10.6008/CBPC2595-4318.2018.001.0004 


\section{INTRODUÇÃO}

Com a globalização, o mercado de trabalho de bens, produtos e serviços tornou-se mais competitivo. O avanço tecnológico na área das comunicações é, porque não dizer, o maior responsável pelas grandes mudanças nas relações socioeconômicas, políticas e culturais em boa parte do mundo, onde a tecnologia se faz presente, sendo que uma dessas mudanças diz respeito ao comportamento dos consumidores e usuários de bens e serviços, tanto do meio público quanto privado.

Neste entendimento, surgem as narrativas de Kotler et al. (2006), ao identificar que nas diversas empresas, as grandes competitividades estão ligadas aos desafios e oportunidades da sociedade atual, a saber: a globalização, os avanços tecnológicos e a desregulamentação. Esses têm se tornado forças de novos comportamentos e desafios, fazendo existir, cada vez mais, qualidade e serviços superiores, obrigando as organizações a sempre buscarem se ajustar às novas exigências dos clientes, que estão mais informados e atualizados sobre os produtos e serviços, permitindo-lhes uma compra mais racional.

Para Portaluppi et al. (2006) "a velocidades dessas transformações, [...] tem estimulado as organizações a unirem forças internas e externas, e transformar esses desafios em oportunidades de negócios". Esse novo perfil de cliente levou o mundo dos negócios e prestadores de serviços a adotarem políticas de gestão de qualidade, visando à satisfação, fidelização e conquista de antigos e novos clientes. Diante do avanço das Tecnologias da Informação e Comunicação - TIC, os governos também se viram obrigados a repensarem as formas de relação com a população.

Novas políticas de gestão pública precisaram ser adotadas, pois o cidadão se tornou mais exigente quanto às ações governamentais, especialmente no que diz respeito ao uso do dinheiro público. Conforme Longo (1996), o mundo moderno vem sendo objeto de profundas e aceleradas transformações, que envolvem os setores econômicos, políticos e sociais, o que tem levado as nações e seus governos a adotarem estratégias diferenciadas e criativas para elevar a qualidade de vida de suas populações.

No Brasil, a criação do portal da transparência é uma ação do Governo Federal que tem o intuito de dar credibilidade às ações do governo, no que diz respeito à forma como é utilizado o erário. O Portal da Transparência do Governo Federal é uma iniciativa da Controladoria-Geral da União (CGU), lançada em novembro de 2004, para assegurar a boa e correta aplicação dos recursos públicos. O objetivo é aumentar a transparência da gestão pública, permitindo que o cidadão acompanhe como o dinheiro público está sendo utilizado e ajude a fiscalizar a sua aplicação (BRASIL, 2017). Dessa forma, o usuário sente-se mais satisfeito em poder acompanhar e analisar de perto como são desenvolvidas as políticas de melhorias para o setor, buscando a qualidade em serviços e produtos disponibilizados para si.

Apesar de todos os esforços dos gestores públicos brasileiros para conquistar a confiança dos seus cidadãos, a realidade é oposta. A insatisfação com a qualidade dos serviços prestados pelos órgãos e instituições públicas é generalizada. Tal fato pode ser constatado por qualquer indivíduo em uma conversa informal com seus pares ou não. É comum, nos meios de comunicação e nas mídias sociais, consumidores/clientes e até funcionários do próprio governo e prestadores de serviços, denunciarem ou 
manifestarem sua insatisfação com a má qualidade de boa parte dos serviços prestados pelos órgãos públicos. De igual modo, há servidores públicos despreparados e não qualificados, a precariedade de serviços, as péssimas condições de trabalho em órgãos e instituições públicas, a estrutura física dos espaços públicos, principalmente aqueles voltados para o atendimento à população de baixa renda estão entre as principais reclamações dos usuários e consumidores de bens e de serviços públicos.

Embora conste na Constituição Federal, no caput do artigo 37, e na Emenda Constitucional n. 19, o qual trata sobre o Princípio da Eficiência, "enquanto princípio da Administração destacando os meios de alcançar a qualidade do serviço público" (MORAIS, 2009), a gestão pública ainda deixa a desejar no quesito qualidade de serviços e atendimento ao consumidor/usuário.

Dentre as instituições públicas que apresentam precariedade e/ou ineficiências na prestação de serviço estão as bibliotecas públicas. Segundo o manifesto da International Federation of Library Associations and Institutions (IFLA) e da Organização das Nações Unidas para educação, Ciência e Cultura (UNESCO), "a biblioteca pública é o centro local de informação, disponibilizando prontamente para os usuários todo tipo de conhecimento". Ainda, que os serviços fornecidos pela biblioteca pública baseiam-se na igualdade de acesso para todos, independentemente de idade, raça, sexo, religião, nacionalidade, língua ou status social. Serviços e materiais específicos devem ser fornecidos para usuários inaptos, por alguma razão, a usar os serviços e materiais regulares, por exemplo, minorias linguísticas, pessoas deficientes ou pessoas em hospitais ou prisões.

Esse estudo visou a apresentar o tratamento do problema sobre a avaliação da qualidade em serviços oferecidos por bibliotecas públicas, buscando identificar a qualidade percebida pelos usuários na utilização dos serviços na Biblioteca em referência. O presente estudo tem por objetivo analisar o fator de qualidade nos serviços oferecidos pela biblioteca, segundo a ótica dos usuários, pois se entende que a satisfação do usuário o leva a ser um frequentador assíduo e fiel ao espaço, além de um multiplicador de informações. “Encorajar os usuários a avaliar constantemente os serviços oferecidos pela biblioteca é uma das abordagens mais úteis para se encontrar as evidências que irão nortear a melhoria da qualidade".

Com o objetivo apresentado, a expectativa, ao observar a gestão em uma Biblioteca, foi de verificar os serviços oferecidos em uma unidade que necessita de melhorias, tornando-os mais acessíveis à comunidade onde ela está inserida, a fim de promover crescimento e comodidade para o usuário. Essas ações de melhorias resultam em válidas contribuições para a comunidade em geral, e também contribuem para uma vida alinhada à inclusão e à educação digital, propondo reais mudanças no intuito de ajustar os serviços prestados à qualidade esperada pelos usuários da biblioteca pública.

\section{REVISÃO TEÓRICA}

\section{Biblioteca Pública}

A biblioteca pública, por ser uma instituição que desempenha um papel fundamental para o desenvolvimento sociocultural da sociedade, promovendo oportunidade de acesso à informação e 
construção do conhecimento, é fundamental à implantação de métodos de administração, os quais considerem os fatores de satisfação humana, entendendo que: a biblioteca pública é uma instituição com uma missão desafiadora, cujo principal propósito é ser uma fonte de informação confiável para a comunidade na qual está inserida. Para cumprir essa missão, no entanto, são necessárias estratégias que possibilitem a realização dos serviços de maneira satisfatória (PALLETA et al., 2015).

A biblioteca pública é "agente essencial na promoção da paz e bem-estar espiritual da humanidade", segundo UNESCO. No entanto, o poder público, responsável pela gestão desses espaços de informação, não parece compactuar de tal crença ou desconhece o potencial desses centros de informação. Poucos são os Estados brasileiros que utilizam recursos financeiros e pessoais qualificados para ampliação e melhorias das suas bibliotecas públicas e nos serviços prestados por elas.

De acordo com a Federação Internacional das Associações e Instituições Bibliotecárias (IFLA), sobre Internet "[...] o livre acesso à Internet, oferecido pelas bibliotecas e serviços de informação, contribui para que as comunidades e os indivíduos atinjam a liberdade, a prosperidade e o desenvolvimento [...]". E ainda que "[...] a liberdade de acesso à informação, independentemente de suporte e fronteiras, é uma responsabilidade primordial da biblioteca e dos profissionais da informação [...]". Desse modo, a biblioteca deve estar apta para atender a todos, sem distinção de raça, religião, cultura, política, gênero, entre outras condições. $\mathrm{O}$ acesso à informação é um direito de todo cidadão, a biblioteca pode e deve fazer uso das tecnologias da informação e comunicação (TIC) para auxiliar no desenvolvimento de seus serviços e no alargamento de suas atividades.

A biblioteca pública é uma instituição fundamental na luta contra a desigualdade social e o acesso às TIC, visando, assim, diminuir essa exclusão. Porém, o primeiro censo nacional das bibliotecas públicas municipais brasileiras, revelou que menos de $1 / 3$ das bibliotecas do Nordeste tem Internet (28\%), índice inferior à média nacional (45\%). Em apenas 18\% das bibliotecas públicas municipais brasileiras os usuários têm acesso à rede, número também inferior à média brasileira (29\%).

Diante das dificuldades que a biblioteca pública enfrenta, a busca por mecanismos de melhoria é essencial. Segundo Palleta et al (2015), um fator que pode contribuir para a qualidade nos processos de gestão das bibliotecas públicas é a observação e implantação das normas da ABNT NBR ISO 9001 . A ISO 9001 é a "norma que define os requisitos para colocar um sistema de gestão de qualidade em vigor. Ela ajuda a empresa a aumentar a sua eficiência e a satisfação do cliente." (ABNT, 2015).

Já Cavalcante (2010) sustenta que a gestão das bibliotecas públicas deve compreender o "processo de gerenciar com inovação e liderança o capital estrutural, informacional e intelectual, rumo à consolidação de seus objetivos, de modo a atender satisfatoriamente as necessidades do público de usuários [...]". Desse modo, entende-se que as instituições públicas visam levar ao seu público específico, um serviço de qualidade e que alcance a satisfação integral, atendendo a requisitos mínimos preestabelecidos, mas focados na individualidade da comunidade em que está inserido o órgão prestador de serviços. 


\section{Conceitualização da gestão de qualidade}

Dentro do que Paladini (2009) propõe, no que tange à gestão da qualidade, vale frisar o quanto essa temática é fundamental para a organização, sendo uma "chave" para que sejam ofertados serviços de padrão elevado e que atendam às necessidades e expectativas dos clientes. Com esta ênfase, discutiu-se qualidade total, a gestão da qualidade no processo e as abordagens práticas que determinam diferenciais competitivos das organizações, convergindo para o impacto social da qualidade. A seguir, são apresentados os métodos e as estruturas da Gestão da Qualidade, mostrando como estruturar a qualidade desde o projeto, as formas práticas de avaliar os elementos da qualidade no produto, as diferentes noções de planejamento e controle da qualidade (PALADINI, 2009).

A estrutura de suporte e o modelo econômico da Gestão da Qualidade são também considerados, sempre sob um viés estratégico. Ainda para Paladini (2009), "o processo gerencial da qualidade é descrito em termos de seus elementos fundamentais: o processo de tomada de decisão, o perfil do agente de decisão, o envolvimento dos recursos humanos no esforço pela qualidade e o componente cultural que determina a consolidação da gestão da qualidade nas organizações".

Segundo Garvin (1992), o desenvolvimento das abordagens da qualidade foi surgindo aos poucos, de modo regular, e não de inovações marcantes, consistindo em produtos de uma série de descobertas que remontam há um século atrás, sendo que nos Estados Unidos, tais descobertas podem ser organizadas em quatro 'eras da qualidade' distintas: inspeção, controle estatístico da qualidade, garantia da qualidade e gestão estratégica da qualidade. A partir destes períodos é possível analisar a evolução do tema qualidade, suas abordagens, principais referências, transformações e diferentes percepções encontradas acerca do tema, fatores estes que construíram os moldes da gestão da qualidade de hoje.

\section{A Influência da gestão de qualidade para com os serviços na biblioteca}

Uma das grandes influências da gestão da qualidade em bibliotecas públicas está nos propósitos apresentados e no trabalho realizado dentro delas, trazendo aos usuários tranquilidade em suas buscas em pesquisas, seu funcionamento eficiente e a transparência dos funcionários no compartilhar seu saber com todos. Segundo Abreu (1991), os resultados de uma organização estão intimamente relacionados com a sua qualidade total, ou seja, organizações que não possuem qualidade total não têm condições de obter resultados compensadores.

Ainda segundo Abreu (1991), da mesma forma que exercem papel preponderante na otimização dos resultados, os empregados são os principais agentes de busca de qualidade total da empresa, já que é através deles que se conseguirá a qualidade dos recursos existentes na organização. Segundo Silva (1996), presumese que o ambiente da qualidade é preocupação de todos que adotam a filosofia da qualidade, e não tem relação direta com o sistema gerencial em particular; esse ambiente não é uma questão teórica, mais uma questão prática. A verdadeira filosofia da qualidade deve permear, de forma visível, o ambiente físico e social da organização. 


\section{A satisfação dos usuários nos serviços oferecidos na biblioteca}

Quando se observa a satisfação do cliente - ou usuário - de certo serviço/produto, pode-se destacar que nos últimos tempos ela tem evoluído conforme as mudanças constantes do mercado e se mostram como "uma das principais formas das organizações conquistarem mercado, ocorrendo a partir da captação e relacionamento dos mesmos", conforme afirmação de Ribeiro (2008) em suas ponderações acerca do tema. A globalização econômica resulta em constantes transformações mercadológicas. Os clientes ficam mais exigentes e consequentemente as empresas buscam aprimorar conhecimento e qualidade, tendo como principal objetivo a satisfação de seus consumidores (RIBEIRO, 2008).

O papel exigido para alcançar a satisfação do cliente está estreitamente ligado ao modo como os serviços e produtos são entregues pela empresa. Sendo, principalmente, a qualidade no ato do atendimento a percepção do grau de satisfação obtido na entrega daquele serviço para o cliente, tornando-se imprescindível essa relação para o sucesso de qualquer organização.

No setor público, especialmente nas bibliotecas, Oliveira (2004) salienta que os serviços ofertados aos seus usuários devem levar em consideração a valoração, e parte disso é através da integração entre o ambiente físico, os processos e os procedimentos que uma organização realiza, transformando um único momento em algo positivo ou não, ou seja, torna-se um momento da verdade sobre o grau de satisfação que poderá ser alcançado.

\section{METODOLOGIA}

Para alcançar os objetivos propostos por esse artigo, foi utilizada como metodologia de pesquisa a bibliográfica. Que, segundo Markoni et al. (2010), a pesquisa bibliográfica "abrange toda bibliografia já tornada pública em relação ao tema estudado" desde as publicações na forma escrita como na forma oral. Conforme os autores, essa técnica de pesquisa tem como "finalidade colocar o pesquisador em contato direto com tudo que já foi escrito, dito ou filmado" sobre o assunto pesquisado. A pesquisa bibliográfica permitiu a compreensão do tema proposto, por meio da leitura de artigos, teses e dissertações em periódicos digitais disponíveis em bases de dados e em literatura especializada, oferecendo as bases para a construção desse artigo, com a finalidade de fundamentar e embasar a pesquisa.

Aliada à pesquisa bibliográfica utilizou-se a pesquisa de campo, do tipo exploratória, tendo como procedimento o uso de coleta de dados por meio de um questionário aplicado ao público alvo, que, segundo Gil (1999), este método possui o objetivo de identificar os fatores da ocorrência de um fenômeno. No caso em questão, aos usuários de uma Biblioteca Pública, com o fim de investigar o nível de satisfação desses usuários em relação aos produtos e serviços oferecidos pela já referida instituição, além de buscar identificar a percepção dos usuários ao nível de qualidade da unidade.

Utilizou-se, também, para construção desse artigo, o método qualitativo-quantitativo, pois "afastada a ideia de que somente o que é mensurável teria validade científica" (OLIVEIRA, 2011). Sobre o método de pesquisa qualitativo, Oliveira (2011) destaca que este investiga e analisa os dados em um processo indutivo, 
alinhando a tentativa de capturar a 'perspectiva dos participantes', examinando-se como os entrevistados encaram as questões que estão sendo focalizadas. Já o quantitativo, por apresentar coleta de dados estruturados e informações estatísticas foca no tratamento da análise de números de casos representativos.

O método quantitativo permitiu fazer um levantamento percentual dos usuários satisfeitos e dos não satisfeitos com a qualidade dos serviços e produtos prestados pela instituição. O método qualitativo permitiu, por meio da coleta e avaliação dos dados, identificar o nível da qualidade dos serviços e produtos oferecidos na biblioteca. Na descrição dos fatores da qualidade será observada a estrutura gerencial e suas funcionalidades.

A pesquisa tem uma parte bibliográfica e outra prática, desenvolvida por meio de fontes humanas. Teve um questionário elaborado com um total de 19 questões, sendo que na primeira parte da pesquisa foi realizada a identificação do perfil dos entrevistados, com perguntas sobre as informações do respondente sobre sexo, idade, escolaridade, estimativa de tempo gasto para consultas ou empréstimos na Biblioteca e seu local de origem. Em sua segunda parte, o questionário apresentou 17 questões relacionadas à frequência de utilização dos espaços da unidade, facilidades de empréstimos, livros disponíveis, consultas físicas e online quanto a pesquisa, acessibilidade, além de questões sobre o atendimento aos usuários, infraestrutura da unidade, medição do nível de satisfação dos usuários em diversas áreas e a comparação com outros órgãos do mesmo setor.

Por fim, os entrevistados foram questionados sobre possíveis sugestões de melhorias à biblioteca e identificação de pontos fortes nos serviços e produtos oferecidos pela unidade. Sendo que a amostra foi composta pelos usuários que compareceram à Biblioteca no mês de outubro, sendo requisito de inclusão aceitar responder a pesquisa. Foram excluídos todos os questionários não preenchidos na íntegra.

\section{RESULTADOS E DISCUSSÃO}

\section{Do perfil dos usuários}

A pesquisa abordou diversos itens e fatores relevantes na busca pela identificação da satisfação dos usuários dos serviços e produtos ofertados pela Biblioteca Pública, identificando tanto o nível de percepção dos usuários quanto a qualidade dos serviços e produtos da unidade. A coleta de dados da pesquisa ocorreu na própria biblioteca, entrevistando os usuários dos serviços e produtos, sendo em um total de 36 o número de pessoas que se dispuseram a responder os questionários. Inicialmente, apresenta-se o perfil dos usuários entrevistados, tendo sido focalizado o local de origem, gênero, idade e qual o tempo gasto dentro das instalações da biblioteca.
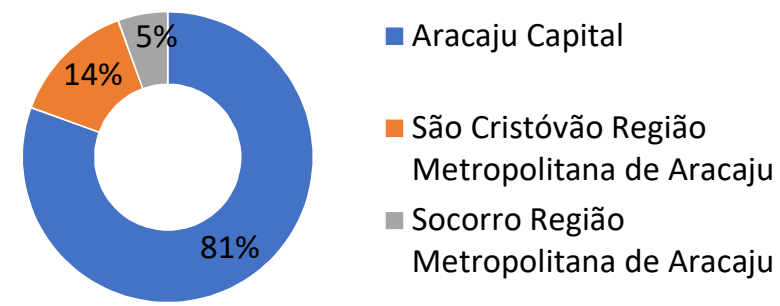

Gráfico 1: Local de Origem. 
No gráfico 1, pode-se identificar que os entrevistados que utilizam os serviços da biblioteca são residentes, em sua maioria, da capital sergipana, Aracaju, totalizando assim $81 \%$, seguidos do total de $19 \%$ dos usuários das regiões metropolitanas de Aracaju. Sendo que desse total das regiões metropolitanas fazem parte $14 \%$ da cidade de São Cristóvão, enquanto os 5\% provindos da cidade de Nossa Senhora do Socorro.

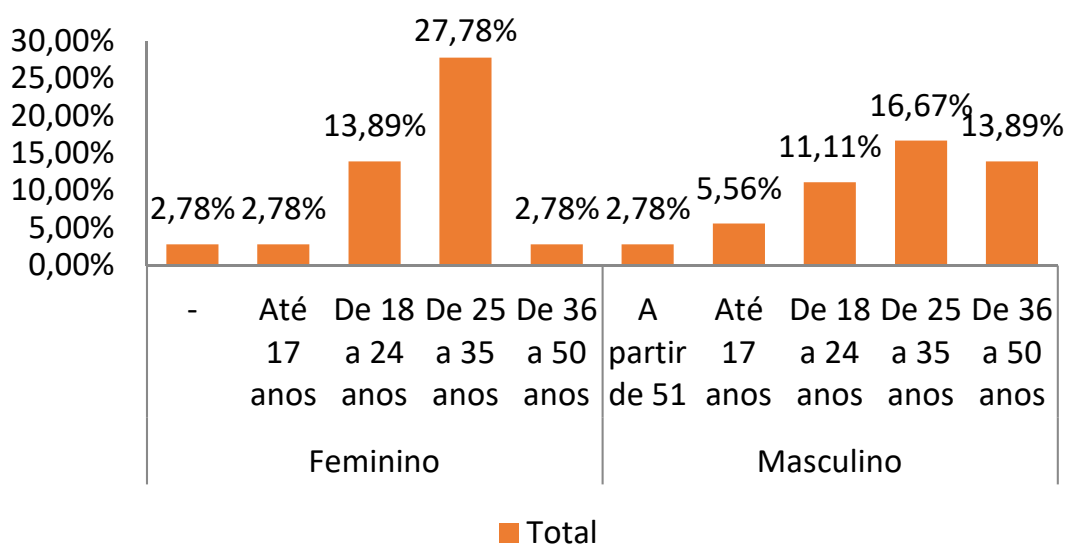

Gráfico 2: Gênero vs Idade

Neste outro gráfico, pode-se observar que os entrevistados são: 50\% constituídos do sexo masculino e a outra parte, $50 \%$, do sexo feminino. Na identificação dos gêneros e idades, foram cruzados os dados para uma análise diferenciada do perfil desses, onde demostram que $16 \%$ dos entrevistados são do sexo masculino e predominam com a idade de 25 a 35 anos; outros 13\% possuem de 36 a 50 anos de idade; ainda 11\% entre 18 a 24 anos; $5 \%$ até 17 anos; e, a partir de 51 anos, o restante de $2 \%$. Neste sentido, no gênero feminino a predominância também está na faixa etária de 25 a 35 anos; seguida de $13 \%$ de 18 a 24 anos; e 2\% de 36 a 50 anos e 2\% na faixa-etária até 17 anos não souberam ou não opinaram (GRÁFICO 2).

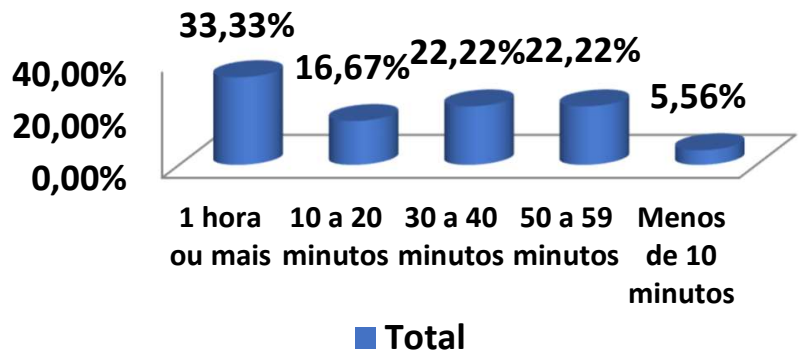

Gráfico 3: Tempo médio gasto dentro da biblioteca

Ainda na identificação dos perfis dos entrevistados, é analisado qual o tempo médio que os usuários da Biblioteca passam dentro das instalações da unidade para realização das suas pesquisas, empréstimos de livros, consultas a exemplares e utilização dos diversos espaços da biblioteca. No gráfico 3, foram apresentados os dados coletados da seguinte forma: constituindo sua maioria, parte dos usuários, no total de $33 \%$ gastam 1 hora ou mais nas instalações da unidade, seguida de $22 \%$ das pessoas que gastam o tempo médio de 30 a 59 minutos, e dos $16 \%$ que usam de 10 a 20 minutos e, por último, aqueles que frequentam menos de 10 minutos a unidade, com um percentual de $5 \%$. 


\section{Frequência da utilização dos serviços da biblioteca}

Para melhor entender os usuários e poder avaliar os resultados quanto à satisfação, coletaram-se os dados da frequência em que essas pessoas utilizam os serviços e produtos ofertados por este órgão (GRÁFICO 4). Desse modo, identificaram-se níveis de utilização dos serviços da biblioteca, sendo no percentual de $44 \%$ os usuários que frequentam de forma moderada, outros 36\% com muita frequência. Apenas 13\% usam de pouca frequência e, por fim, $5 \%$ de extrema frequência dos ofertados.

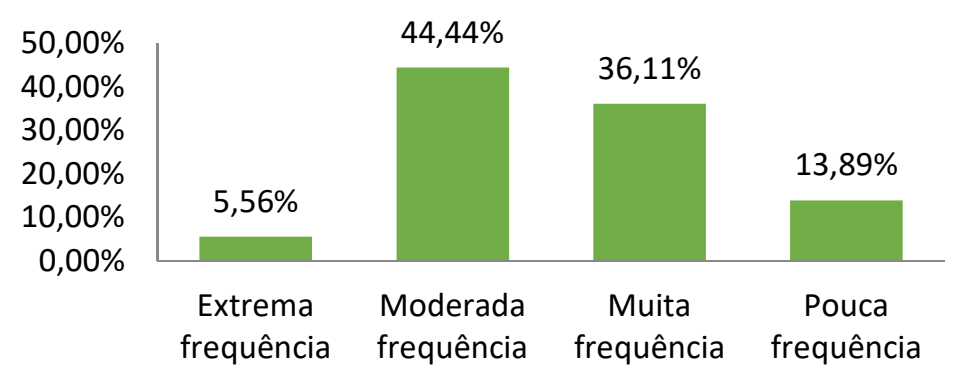

Gráfico 4: Frequência da utilização dos serviços

\section{Fácil acesso na obtenção de empréstimos de livros no acervo da Biblioteca}

Em atenção à infraestrutura organizacional disponível aos usuários, quanto aos livros do acervo, foram levantados os dados relacionados com a existência de facilidade das pessoas para conseguir empréstimo de um exemplar qualquer no acervo da unidade. O gráfico 5 demostra: que em $41 \%$ dos casos os usuários acreditam ser moderadamente fácil encontra um exemplar; posteriormente, cerca de $38 \%$ encontram com muita facilidade; outros $13 \%$ dizem ser extremamente fácil e, em sua minoria, 5\% afirmam ser de pouca facilidade.

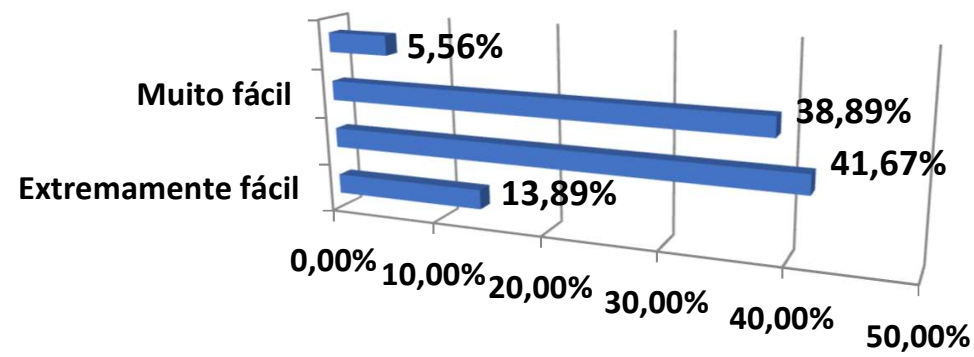

Gráfico 5: Facilidade de empréstimos de livros

\section{Facilidade em obter os recursos que necessitam no acervo da Biblioteca}

Visando atender às necessidades individuais dos usuários, a pesquisa teve a preocupação de coletar dados quanto à satisfação perante a obtenção dos recursos que necessitam dentro do acervo, avaliando as expectativas da facilidade em sua obtenção. Com predominância absoluta, mais de $55 \%$ dos usuários apontam ser moderada a facilidade de obtenção dos recursos que necessitam no acervo da biblioteca, sendo que $31 \%$ dizem ser de muita facilidade, $11 \%$ de extrema facilidade e apenas $3 \%$ consideram ser de pouca facilidade. 


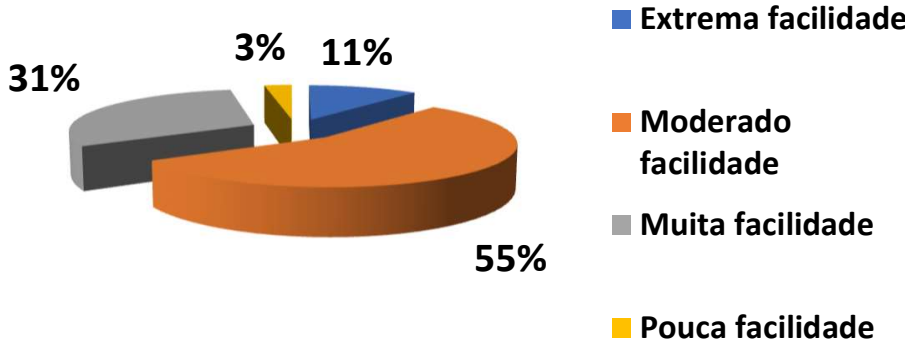

Gráfico 6: Recursos que necessitam no acervo

\section{Facilidade em encontrar um exemplar no acervo da Biblioteca}

Quanto à disposição dos livros, prateleiras e organização dos corredores de exemplares, foram questionados sobre a facilidade de uma pessoa encontrar um exemplar na unidade. Fica evidente, no gráfico 7, que os usuários acreditam, em sua maioria, que é moderadamente fácil encontrar esses exemplares junto à unidade, num percentual de $55 \%$. Já outros $25 \%$ dos entrevistados relatam ser muito fácil essa obtenção. Com o índice de $11 \%$, outros usuários dizem ser pouco fácil e apenas $8 \%$ alegam que é extremamente fácil encontrá-los.

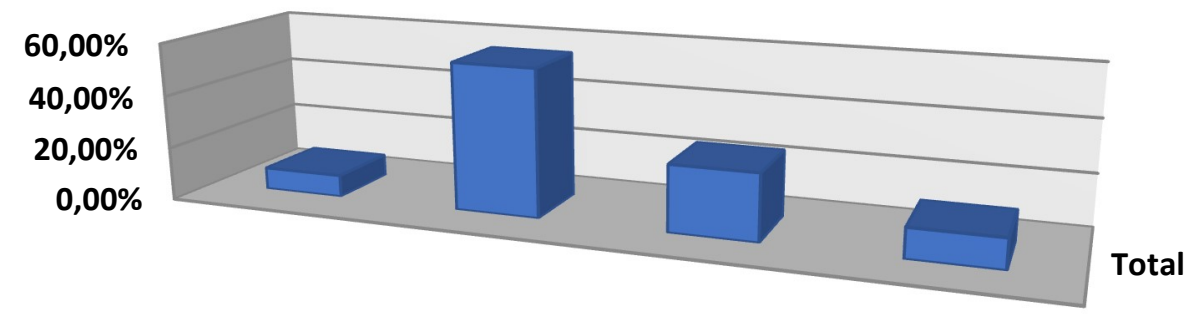

\begin{tabular}{|l|c|c|c|c|}
\cline { 2 - 5 } & $\begin{array}{c}\text { Extremamente } \\
\text { fácil }\end{array}$ & $\begin{array}{c}\text { Moderadamente } \\
\text { fácil }\end{array}$ & Muito fácil & Pouco fácil \\
\hline$\square$ Total & $8,33 \%$ & $55,56 \%$ & $25,00 \%$ & $11,11 \%$ \\
\hline
\end{tabular}

Gráfico 7: Facilidade em encontrar um exemplar no acervo

\section{Acessibilidade ao acervo da Biblioteca para os usuários com necessidades especiais}

Foi questionado se a biblioteca está de acordo com as normas de acessibilidade para pessoas com necessidades especiais a partir da visão dos entrevistados que frequentam a unidade. Dessa forma, são apresentados os seguintes resultados: 53\% dos usuários dizem estar moderadamente acessível; outros 19\% dizem ser muito acessível; ainda assim, 14\% dos entrevistados identificam que está pouco acessível, sendo que $6 \%$ dizem estar extremamente acessível.
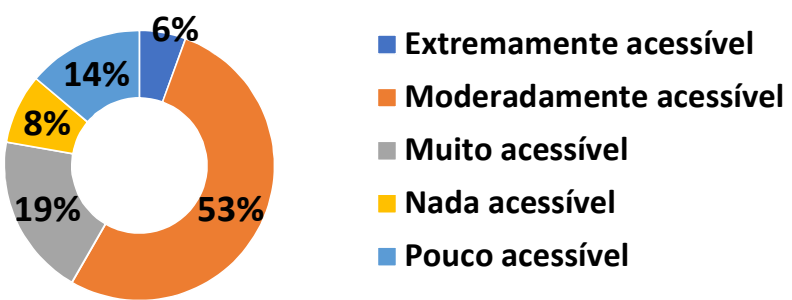

Gráfico 8: Acessibilidade para os usuários 
O ponto que a biblioteca leva em consideração às necessidades pessoais dos usuários

Outro ponto que destaca-se versa sobre a observância de gestão da unidade, quanto às considerações pessoais dos indivíduos ao se relacionarem e apontarem sugestões para melhoria da organização, em função de sua necessidade como usuário de um serviço de caráter público. 0 gráfico 09 demonstra: que cerca de $44 \%$ dos usuários, levados em consideração, avaliam de forma moderadamente bem; outros $30 \%$ muito bem; e, $13 \%$, extremamente bem. Já cerca de $11 \%$ expõem que são pouco bem considerados.

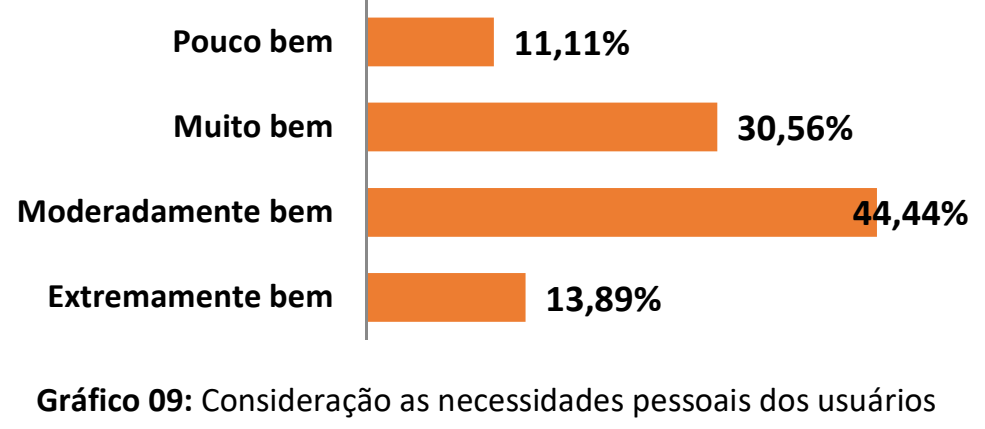

Nível de satisfação com a climatização do ambiente interno da biblioteca

A climatização do ambiente interno da Biblioteca é outro ponto muito relevante para os usuários. A coleta de dados apresenta o maior índice de insatisfação. São 36\% dos entrevistados que apontam estarem pouco satisfeitos com a climatização da unidade, outros mais de $27 \%$ se encontram com moderada satisfação, sendo que 19\% apresentam total insatisfação nesse quesito. Apenas 11\% dos usuários estão muito satisfeitos, enquanto $5 \%$ com extrema satisfação.

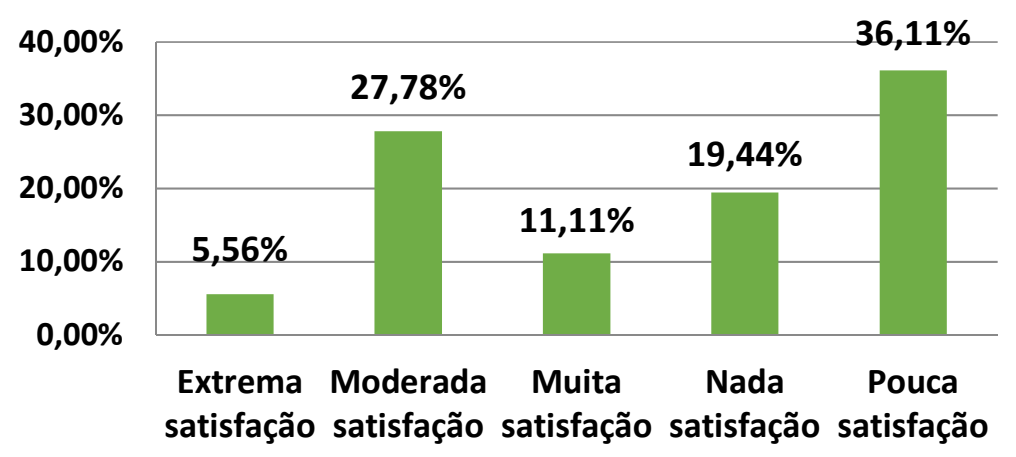

Gráfico 10: Satisfação com a climatização do ambiente

\section{Nível de satisfação com o conforto do ambiente de estudos da biblioteca}

Já quando os entrevistados são abordados sobre a sua satisfação com o ambiente de estudos disponibilizado pela unidade, são pontuados $47 \%$ de pessoas moderadamente satisfeitas com o conforto do ambiente, enquanto mais de $27 \%$ apresentam pouca satisfação e outros $19 \%$ se dizem satisfeitos. Já a minoria de $5 \%$ atesta estar extremamente satisfeita (GRÁFICO 11). 


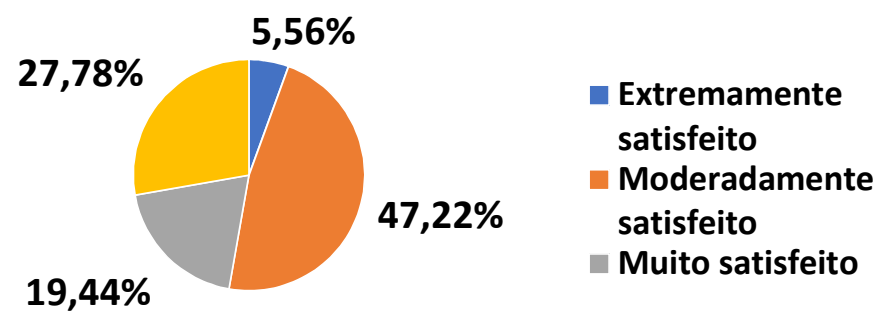

Gráfico 11: Satisfação com o conforto do ambiente

\section{Acesso aos computadores, que compõem o Telecentro, para a sua realização de pesquisas}

O 'Telecentro' é um espaço destinado aos usuários terem acesso livre a pesquisas, consulta e realizações de estudos, com uma estrutura que possui computadores ligados à rede mundial de computadores, através da internet. Pode-se observar (GRÁFICO 12), que os dados coletados apontam que cerca de $33 \%$ dos entrevistados relatam ser pouco acessível esse espaço, outros $25 \%$ indicam que é moderadamente acessível, e 22\% muito acessível. Enquanto isso, cerca de 16\% sustentam que o Telecentro é nada acessível e apenas $2 \%$ dizem ser extremamente acessível.

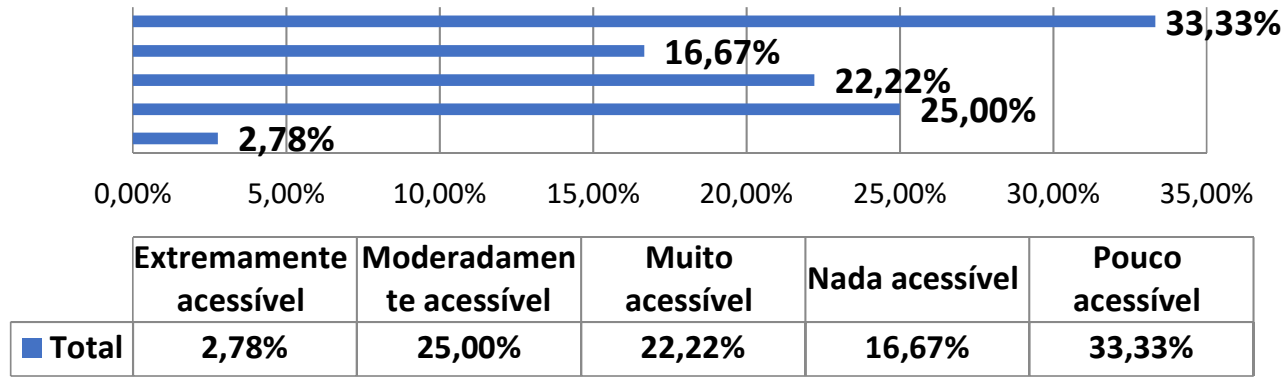

Gráfico 12: Acesso aos computadores para pesquisas

\section{Sistema de pesquisa de exemplares on-line, através de site, probabilidade de consultas}

Atualmente, a biblioteca não dispõe de consultas de exemplares em um sistema operacional informativo on-line. Na busca pela identificação do nível de aceitação da implementação de um sistema informacional como este, a pesquisa questionou aos entrevistados qual seria a probabilidade de consultas a serem realizadas. Neste sentido, pode ser identificado no gráfico 13 que uma grande maioria dos usuários, $58 \%$, consideram a realização de uma consulta on-line muito provável, enquanto outros $25 \%$ acreditam moderadamente provável realizar. Pouco mais de 13\%, acusam que seria extremamente provável a sua utilização, e apenas $2 \%$ indicam ser pouco provável o uso.

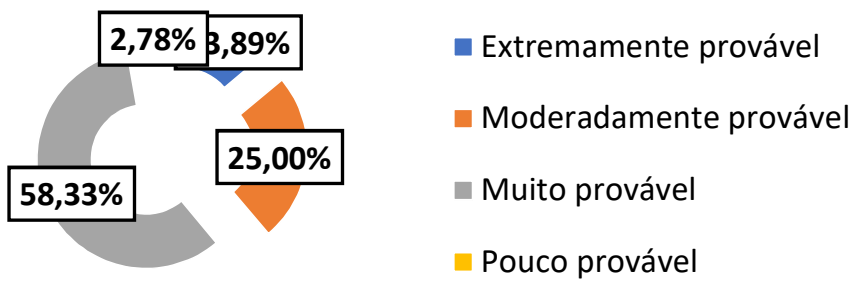

Gráfico 13: Pesquisa de exemplares on-line 


\section{Frequência que alguém deu uma satisfação sobre a possível demora ou de tempo de espera}

No sentindo de analisar se o atendimento ao público está sendo bem realizado pelos colaboradores atuais da unidade, buscando alcançar a satisfação dos usuários, foram coletados dados quanto à frequência que algum dos atendentes deu uma satisfação, explicação ou uma resposta ao usuário sobre a demora ou de quanto tempo seria a espera para obtenção ou empréstimo de um livro. Segundo o gráfico 14, 36\% dos usuários dos serviços da biblioteca dizem que receberam uma resposta dos atendentes sobre a espera ou demora para a obtenção ou empréstimo de um livro. Mas, 36\% dos entrevistados acusam só ter recebido esta satisfação/reposta do tempo de espera algumas vezes, outros $16 \%$ apontam nunca ou na maioria das vezes.

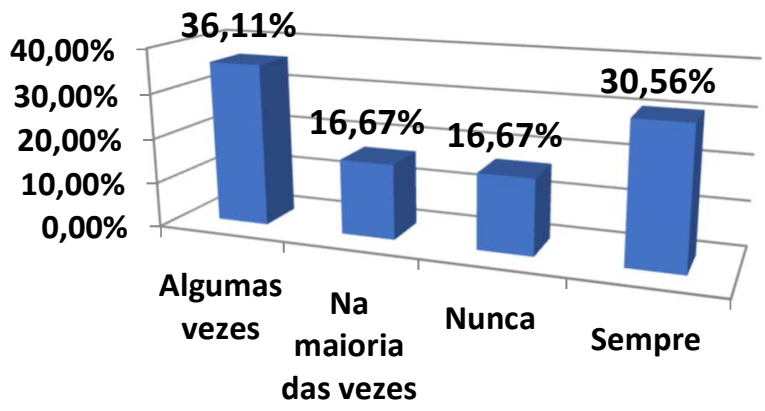

Gráfico 14: Satisfação quanto a espera ou demora

\section{Espera até que um dos atendentes dê suporte ao usuário}

Neste quesito, foi investigado o tempo de espera dos usuários da biblioteca por um atendente ir dar atenção. É apresentado, no gráfico 15, que mais de $58 \%$ dos entrevistados aguardam pouco tempo para o atendimento, outro dado mostra que $30 \%$ esperam não muito tempo. Apenas $8 \%$ relatam já ter ficado muito tempo, e os outros $2 \%$ esperam num tempo médio para o atendimento.

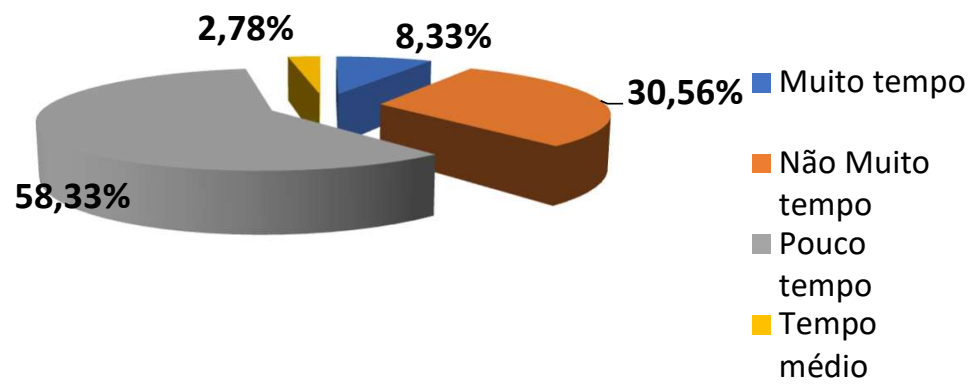

Gráfico 15: Espera para o atendimento

\section{Satisfação ao adquirir um empréstimo de livro junto à biblioteca}

Buscou-se saber qual o nível de satisfação dos usuários quando da realização de um empréstimo de livro junto à unidade, compreendendo a satisfação plena como sendo o atendimento na hora que vai realizar obtenção de um livro. Nesta pesquisa, conseguiu-se identificar que $52 \%$ das pessoas estão moderadamente satisfeitas ao adquirir um empréstimo, que mais de $38 \%$ encontram-se muito satisfeitos, outros $5 \%$ estão como esperado, e os $2 \%$ estão um pouco satisfeito. 


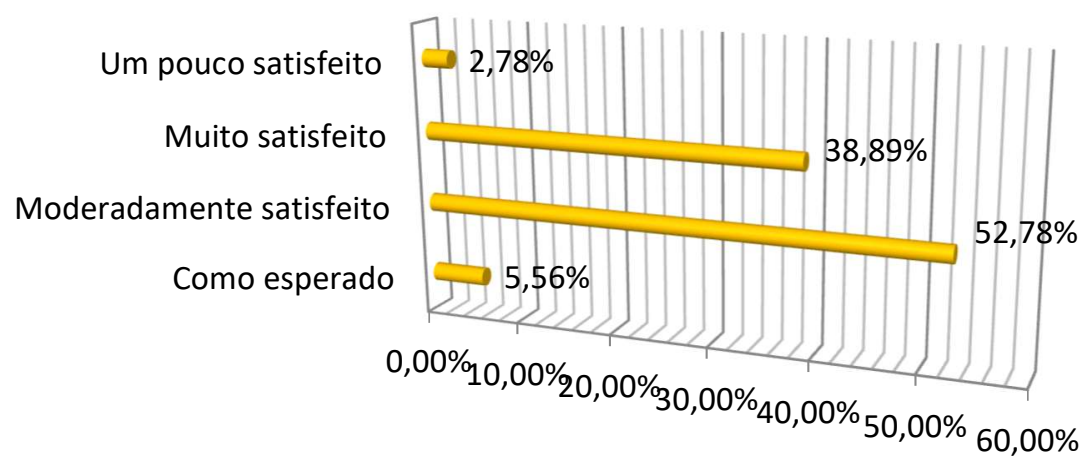

Gráfico 16: Satisfação ao adquirir um empréstimo

\section{Indicação dos serviços oferecidos pela biblioteca a outras pessoas}

Neste quesito, verifica-se qual o nível de indicação para as outras pessoas dos serviços oferecidos pela BPMCS. Ficando demostrado que mais de $52 \%$ dos entrevistados indicariam os serviços, e outros $30 \%$ fariam a indicação na maioria das vezes, enquanto apenas $16 \%$ indicariam em algumas vezes. Sendo assim, fica descartada a opção de "nunca" indicar, por haver $0 \%$.

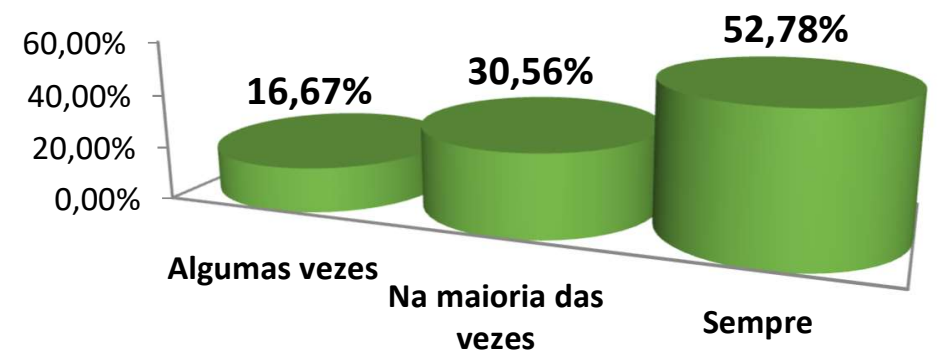

Gráfico 17: Indicação dos serviços

\section{Em comparação a outras bibliotecas públicas, a qualidade dos serviços}

Neste quesito, for questionado aos entrevistados acerca da qualidade dos serviços e dos produtos fornecidos pela Biblioteca, se são superiores, inferiores ou mesmo comparáveis aos de outras bibliotecas públicas. Fica demostrado que $33 \%$ consideram o serviço e os produtos semelhantes; $25 \%$ dizem ser extremamente superior ou moderadamente superior. Outros $8 \%$ dizem ser não muito superior, enquanto $6 \%$ dizem não saber e outros 3\% dizem não ser muito superior.

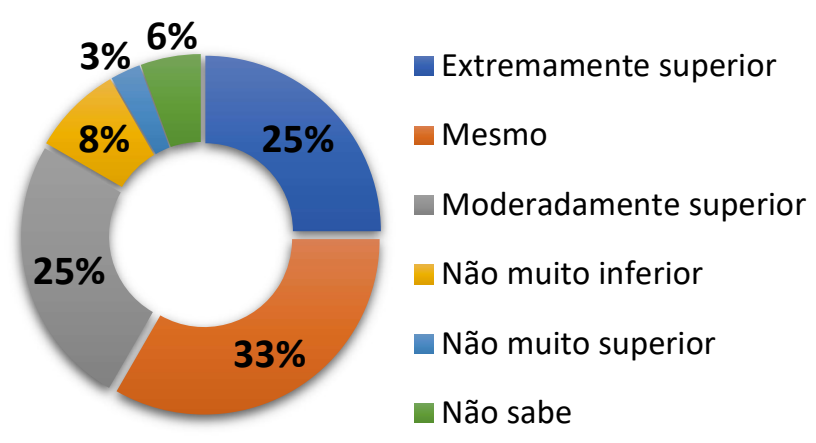

Gráfico 18: Em comparação, a qualidade do serviço 


\section{Conhecimento das programações de eventos da biblioteca ao público}

A biblioteca, através da sua gestão oferece programações de eventos exclusivas para o público em geral, em promoção da arte, cultura e incentivo à leitura. Neste sentindo, a pesquisa se preocupou em identificar qual o nível de conhecimento do público alvo sobre essas programações de eventos ofertados. Assim, verifica-se que $30 \%$ das pessoas pesquisadas têm moderado conhecimento e mais de $27 \%$ têm pouco conhecimento dos eventos proporcionados. Apenas 16\% têm muito conhecimento e outros $5 \%$ não têm nenhum conhecimento.

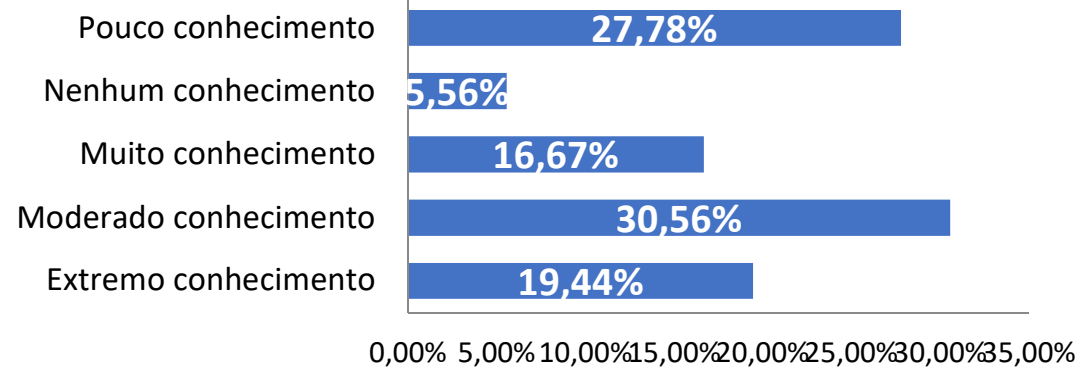

Gráfico 19: Conhecimento das Programações de Eventos

\section{Satisfação com os serviços prestados pela biblioteca}

Nesta análise, verifica-se qual o grau de satisfação da unidade de forma geral, segundo os usuários, para com os serviços e produtos que são oferecidos ao público alvo e obteve-se os seguintes resultados de pesquisa, demonstrados no gráfico 19. Observa-se que 55\% dos entrevistados estão moderadamente satisfeitos com os serviços, outros $25 \%$ se mostram extremamente satisfeitos com a biblioteca, enquanto $8 \%$ nem satisfeitos, nem insatisfeitos, enquanto com percentual de $5 \%$ os outros se mostram pouco satisfeitos e pouco insatisfeitos com o que encontram nesta unidade em seus serviços e produtos ofertados ao público.

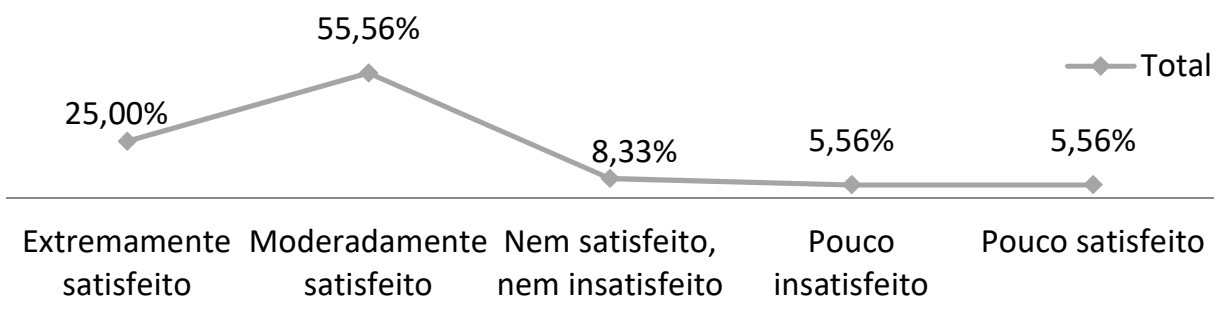

Gráfico 19: Satisfeito ou insatisfeito com os serviços

\section{Pontos de melhoria na unidade}

Através desta questão aberta, de cunho qualitativo, obtiveram-se classes de assuntos mais discutidos e apresentados pelos entrevistados. Desse modo, os assuntos de maior relevância estão apresentados no gráfico 19, sendo destacados os pontos a serem melhorados no órgão: climatização de ambiente, obteve 44\% das manifestações expressas, depois veio a infraestrutura da unidade, com 38\%, sendo este último sobre as manutenções, reformas estruturais e cuidado com o acervo. Já as outras observações apresentadas com um percentual de $5 \%$ fazem referência sobre a acessibilidade, qualidade da gestão e abstenções. 


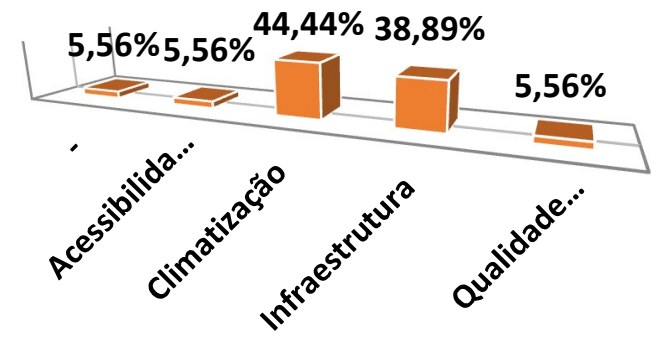

Gráfico 19: Pontos de melhoria

\section{Pontos positivos na unidade}

A identificação dos pontos positivos garante à alta gestão a manutenção corretiva de outras áreas antes esquecidas. Assim, foram identificados os pontos positivos no âmbito do bom atendimento, que recebeu o maior índice de indicação, com o percentual de 52\%. 0 ambiente de Estudos, com $25 \%$, e o acervo disponível na unidade, com um índice de 19\% de aceitação.

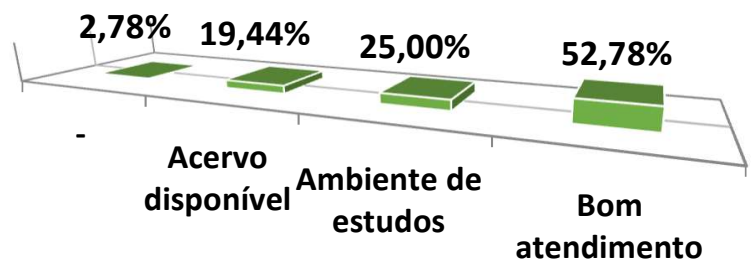

Gráfico 20: Pontos positivos

\section{CONCLUSÕES}

O avanço das tecnologias de comunicação e informação é um dos principais fatores responsáveis pelas grandes mudanças nas relações socioeconômicas, políticas e culturais. Dentre essas mudanças está o novo perfil do consumidor e usuários de serviços públicos. Isto acontece como um resultado do avanço e facilidades de informações sobre o mercado de trabalho, tornando-se bastante competitivos e desafiadores todos os nichos de serviços e produtos destinados ao público. As organizações, as empresas, por sua vez, devem adotar uma gestão que tenha como principal política a qualidade dos bens e serviços que oferecem a esse novo público mais exigente e consciente das informações mercadológicas.

Este novo modelo de consumidor, que passa a maior parte do tempo conectado às redes sociais, está mais ciente dos seus direitos e bem mais exigente com a qualidade dos serviços, bens e produtos que lhe são desejáveis e necessários, pois ele interage mais com outros consumidores por meio dos canais de comunicações disponíveis na internet, ou mesmo pela simples instrução ao seu familiar e amigo. Essa exigência estende-se aos serviços públicos. No caso em questão, às bibliotecas públicas, para a conquista da satisfação dos usuários com os serviços, produtos e estrutura que são ofertados, levando essa exigência como foco para uma gestão estratégica, visando à satisfação do público alvo com as condições e operações da qualidade nos serviços e produtos ofertados.

É bem certo que a forma como as bibliotecas públicas vêm sendo administradas precisa ser repensada, pois toda gestão deve se preocupar com a integração entre o ambiente físico e a execução dos 
processos e procedimentos adotados, sempre na busca pela geração de valor ao usuário dos serviços e produtos. Há um grande desafio para os gestores desses espaços diante da revolução tecnológica da informação e da comunicação. A biblioteca estudada é um exemplo de biblioteca pública possuidora de uma política que promete aos seus usuários uma série de serviços e produtos de qualidade. Porém, a realidade é bem diferente do que promete sua política.

Segundo a pesquisa de campo, realizada por meio da aplicação de questionário, sobre satisfação do usuário, constata-se que eles se encontram satisfeitos em diversos pontos apresentados, como o atendimento e o acervo disponível pela unidade. Porém, destacam a falta de preocupação do Poder Público quanto à infraestrutura das instalações da biblioteca, apontando pontos falhos e de insatisfação, como, por exemplo, a falta de climatização, que prejudicam os estudos e dificultam a permanência, por um longo período, de consultas na instituição.

\section{REFERÊNCIAS}

ABREU, R. C. L.. Círculos de controle da qualidade: a integração trabalho, homem e qualidade total. 2 ed. Rio de Janeiro: Qualitymark, 1991.

ABNT. ABNT NBR ISSO 9001:2015: como usar. Rio de Janeiro, 2017.

ARAÚJO, E. R. O.; VARÃO, A. L. S.. Bibliotecário como gestor de pessoas em unidades de informação. In: ENCONTRO REGIONAL DE ESTUDANTES DE BIBLIOTECONOMIA, DOCUMENTAÇÃO, CIÊNCIA E GESTÃO DA INFORMAÇÃO DAS REGIÕES NORTE E NORDESTE, 17. Anais. Fortaleza, 2014.

BRASIL. Ministério da Transparência e Controladoria Geral da União. Transparência pública. Brasília, 2017.

CAVALCANTE, L. E.. Cultura informacional e gestão de bibliotecas públicas municipais: competências e usos da informação. In: ENCONTRO NACIONAL DE PESQUISA EM CIÊNCIA DA INFORMAÇÃO, 11. Anais. Rio de Janeiro, 2010.

FGV. Fundação Getúlio Vargas. Censo Nacional das Bibliotecas Públicas Municipais: Estudo quantitativo: principais resultados. Brasília: FGV, 2010.

GARVIN, D.. Gerenciando a qualidade: a visão estratégica e competitiva. Rio de Janeiro: Qualitymark, 1992.

GIL, A. C.. Métodos e técnicas de pesquisa social. 5 ed. São Paulo: Atlas, 1999.

IFLA. Federação Internacional de Associações e Instituições Bibliotecárias. Manifesto sobre Internet. Haia, 2002.

IFLA; UNESCO. Federação Internacional de Associações e Instituições Bibliotecárias; Organização das Nações Unidas para a Educação, a Ciência e a Cultura. Manifesto da IFLA/UNESCO sobre bibliotecas públicas. 1994.
KOTLER, P.; KELLER, K. L.. Administração de marketing. 12 ed. São Paulo: Pearson Prentice Hall, 2006.

LONGO, R. M. J.. Gestão da qualidade: evolução histórias, conceitos básicos e aplicação na educação. Brasília: IPEA, 1996.

MARCONI, M. A.; LAKATOS, E. M.. Fundamentos de metodologia científica. 7 ed. São Paulo: Atlas, 2010.

MORAIS, J. J.. Princípio da eficiência na administração pública. Avaré, 2017.

OLIVEIRA, M. F.. Metodologia científica: um manual para a realização de pesquisas em Administração. Catalão, 2011.

OLIVEIRA, O. J.. Gestão da qualidade: tópicos avançados. São Paulo: Pioneira Thonson Learning, 2004.

PALADINI, E. P.. Gestão da Qualidade: Teoria e Prática. 2 Ed. São Paulo: Atlas, 2009.

PALETTA, F. C.. Gestão da qualidade em bibliotecas públicas. Ciência da Informação em Revista, Maceió, v.2, n.2, p.17-28, 2015.

PINTO, A. L.; MOREIRA, G. J. A.. O profissional bibliotecário como gestor de pessoas. Encontros Bibli: Revista Eletrônica de Biblioteconomia e Ciência da Informação, Florianópolis, v.15, n.29, p.52-65, 2010.

PORTALUPPI, J.. Análise do atendimento de satisfação do cliente: estudo de caso de uma empresa agrícola. Revista Científica da UNIPAR, Umuarama, v. 7, n. 1, 2006.

RIBEIRO, H. M.. Qualidade De Atendimento e a satisfação dos clientes da Etitec Automação. Janaúba, 2008.

SILVA, J. M.. O ambiente da qualidade na pratica-5S. Belo Horizonte: Fundação Cristiano Ottomi, 1996.

A CBPC - Companhia Brasileira de Produção Científica (CNPJ: 11.221.422/0001-03) detém os direitos materiais desta publicação. Os direitos referem-se à publicação do trabalho em qualquer parte do mundo, incluindo os direitos às renovações, expansões e disseminações da contribuição, bem como outros direitos subsidiários. Todos os trabalhos publicados eletronicamente poderão posteriormente ser publicados em coletâneas impressas sob coordenação da Sustenere Publishing, da Companhia Brasileira de Produção Científica e seus parceiros autorizados. Os (as) autores (as) preservam os direitos autorais, mas não têm permissão para a publicação da contribuição em outro meio, impresso ou digital, em português ou em tradução. 